\title{
The Impact of Private Insurance Coverage on Prescription Drug Use in Ontario, Canada
}

\author{
Impact de l'assurance médicaments privée sur \\ l'utilisation des médicaments délivrés sur ordonnance \\ en Ontario, Canada
}

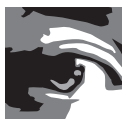

JILLIAN KRATZER

Centre for Health Services and Policy Research

University of British Columbia

Vancouver, BC

LUCY CHENG

Centre for Health Services and Policy Research

University of British Columbia

Vancouver, BC

SARA ALLIN

School of Public Policy E Governance

University of Toronto

Toronto, ON

MICHAEL R. LAW

Centre for Health Services and Policy Research

University of British Columbia

Vancouver, BC 


\begin{abstract}
Canadians obtain prescription drug coverage through a patchwork of public insurance, private benefit plans and out-of-pocket payments. Prior evidence suggests that insurance coverage, in general, leads to higher utilization rates of essential medicines; it is unclear whether individuals with private insurance have better access to medicines.

Using data from the 2008 Canadian Community Health Survey, we identified cohorts from Ontario who reported having been diagnosed by a physician with asthma, high blood pressure or diabetes. Using propensity score stratification techniques, we compared drug utilization of individuals holding private insurance with that of individuals holding either public insurance (for those aged over 65 years) or no insurance (aged under 65 years).

In five out of six comparisons, individuals with private insurance were more likely to take prescribed drugs than those without. Raw differences in the percentage of patients taking medicines ranged from 0.1 to $8.1 \%$.

Ontarians with chronic conditions holding private drug insurance are more likely to use prescription drugs than those who do not. Whether these inequities result in health outcome differences remains unknown.
\end{abstract}

\title{
Résumé
}

La couverture pour les médicaments sur ordonnance au Canada provient d'une mosaïque d'assurances publiques, de régimes d'assurance privés et de déboursements par les particuliers. Des données antérieures suggèrent quén général, la couverture offerte par les assurances mène à des taux plus élevés d'utilisation des médicaments essentiels; cependant, on ne sait pas dans quelle mesure les personnes qui ont une assurance privée jouissent d'un meilleur accès aux médicaments.

À l'aide des données provenant de l'Enquête sur la santé dans les collectivités canadiennes de 2008, nous avons repéré des groupes de patients ontariens qui ont indiqué avoir reçu un diagnostic médical pour l'asthme, l'hypertension artérielle ou le diabète. Au moyen des techniques de stratification des coefficients de propension, nous avons comparé l'utilisation des médicaments chez, d'une part, les personnes détenant une assurance privée et, d'autre part, celles qui détiennent une assurance publique (pour les 65 ans et plus) ou aucune assurance (pour les moins de 65 ans).

Dans cinq des six comparaisons, les personnes qui ont une assurance privée étaient plus susceptibles de prendre des médicaments sur ordonnance que ceux qui nónt pas une telle assurance. Les différences brutes dans les pourcentages de patients qui prennent des médicaments variaient de 0,1 à $8,1 \%$.

Les Ontariens aux prises avec un état chronique et qui détiennent une assurance médicaments privée sont plus susceptibles d'utiliser des médicaments sur ordonnance que ceux qui nont pas une telle assurance. On ne sait pas encore si ces iniquités donnent lieu à des différences dans les résultats cliniques. 


\section{Introduction}

\section{Background}

Unlike all other developed countries with universal healthcare insurance schemes, Canada does not provide universal outpatient prescription drug coverage (Morgan et al. 2013). Rather, Canadians receive prescription drug coverage from a patchwork of different insurance plans, including both public and private plans (Daw and Morgan 2012). Several provinces have agebased drug coverage programs that typically cover the elderly, while others have programs that provide income-based coverage based on deductibles that are a portion of household income (Daw and Morgan 2012). The majority of prescription drug coverage comes from employersponsored drug benefits, which are the primary source of drug coverage for about $60 \%$ of the population (Marshall 2003). The remainder of the population is either covered by public plans or is uninsured (Fraser Group/Tristat Resources 2002). In 2012, public plans paid for approximately $44 \%$ of drug expenditures in Canada, private insurance paid for $35 \%$ and outof-pocket payments made up the remaining 20\% (CIHI 2013).

Much previous work, both in Canada and elsewhere, suggests that the presence and type of insurance coverage - and the resulting lower out-of-pocket costs for patients - is associated with higher utilization of essential medicines (Adams et al. 2001; Joyce et al. 2002; Soumerai 2004; Tamblyn et al. 2001). For example, Goldman and Zheng (2007) synthesized international evidence on the relationship between costs associated with drug benefits and the use of prescription drugs. They found that increased cost sharing (for example, copayments and deductibles) was consistently associated with lower rates of drug use, while patients with diabetes demonstrated that higher cost sharing is associated with an increased use of medical services (Goldman and Zheng 2007). How this impacts drug utilization in Canada, however, is comparatively unstudied. Given the unique stature among other developed nations that provide universal medicare, as being the only nation to also not provide pharmacare, Canada offers an opportunity to study the impact of differences in pharmaceutical coverage without being confounded by differences in out-of-pocket payments required for hospital and physician coverage. To our knowledge, only one study has explicitly examined the relationship between private drug insurance coverage and drug utilization in Canada, which found that seniors in the province of Ontario who held private insurance in addition to the publicly provided insurance had higher use of prescription drugs (Allin et al. 2013).

What remains less clear is how private health insurance impacts drug use in systems with both public and private coverage. Canada provides an ideal setting in which to test such relationships, as some public coverage co-exists with private insurance that generally offers more extensive coverage (Kratzer et al. 2013). About 60\% of Canadians have private insurance, generally as a benefit of employment (Law et al. 2014). To date, research on this topic has been limited. Some evidence suggests that Canadians with private health insurance for prescription drugs have fewer barriers to accessing healthcare than those without. For example, prior 
studies have found that holding private drug coverage was associated with a greater likelihood in accessing physician care and lower patient reports of unmet healthcare needs (Allin and Hurley 2009; Hanley 2009; Stabile 2001). That is to say that despite physician and hospital services being universally publicly provided, the presence of private pharmaceutical drug coverage impacted their use.

While the above-mentioned studies provide an indication that privately insured individuals use more prescription drugs than other Canadians, selection bias remains a significant concern. For instance, we know that higher-income individuals are more likely to hold private drug insurance (Dewa et al. 2005). In contrast, those holding public insurance or those who are uninsured are more likely to have a lower income, be older and use fewer prescription drugs (Dewa et al. 2005; Fang et al. 2008; Millar 1999). This is important because individual characteristics, such as chronic conditions, education, age and income, have all been shown to impact drug utilization (Law et al. 2012; Osterberg and Blaschke 2005). Past studies have used regression techniques to attempt to control for these factors, but it remains unclear how well they have performed. Further, prior work on this topic has aggregated drug use across all therapeutic classes, leaving open the possibility that some differences that have been found were the result of uncontrolled differences in individuals' underlying health conditions (Allin and Hurley 2009; Millar 1999). To investigate the impact of private insurance more robustly, we used propensity score techniques to study the difference in prescription drug use for three cohorts of individuals with and without private drug coverage for three common chronic conditions: asthma, high blood pressure and diabetes.

\section{Methods}

\section{Study context}

In 2008, Ontario's 12.9 million residents (Government of Canada 2012) received comprehensive hospital and physician coverage with no patient charges from the Ministry of Health and Long-Term Care. In contrast, only a portion of residents received prescription drug benefits from Ontario's six drug programs that pay a portion of the cost of their drug charges. Five of the six public programs covered either specific disease groups (e.g., cystic fibrosis, Gaucher's disease and thalassaemia) or specific drugs (e.g., verteporfin, zidovudine and clozapine) (Government of Ontario 2013). The largest program, the Ontario Drug Benefit program (ODB), covered residents who met at least one of the following criteria: aged 65 years or older, lived in a long-term care home, were enrolled in a home care program, had high drug costs relative to their household income (through the Trillium Drug Program) or who received social assistance.

The ODB formulary included around 3,800 drug products and an additional 850 products which required the treating physician to seek special approval from the drug plan. Seniors (aged 65 years and older) with a yearly net income of $\$ 16,018$ or more for a single 
person and $\$ 24,175$ or more for a couple, paid a $\$ 100$ deductible and then up to $\$ 6.11$ per prescription as copayment. Those seniors with net income lower than the figures given above for singles and couples paid up to $\$ 2$ as a copayment for each prescription (Government of Ontario 2013). The majority of residents aged under 65 years were eligible for public coverage through the Trillium Program. Residents on the Trillium Program paid an annual deductible based on their household income, normally set at $4 \%$ of the household's total net income. This deductible was paid in four equal payments over the year. After the deductible was reached, the Trillium Program beneficiaries paid up to $\$ 2$ as copayment for each prescription (Government of Ontario 2013). In practice, many pharmacies in the province waived fees for those who were required to pay the $\$ 2$ copayment for both the ODB and the Trillium Program plan members.

\section{Data sources}

We used 2008 data from Statistics Canada's annual Canadian Community Health Survey (CCHS), which is the most recent year in which questions on drug coverage were included. The CCHS is a sample survey with a cross-sectional design, and it is collected through telephone interviews using computer-assisted interviewing. Responding to the survey is voluntary and data are collected directly from survey respondents. The CCHS collects information related to health status, healthcare utilization and socio-demographic information for the Canadian population. In 2008, Ontario purchased a supplementary module that included a question asking whether respondents had public, employer-sponsored or private drug coverage (please see Appendix 3 for the relevant questions from the CCHS, at www.longwoods. com/content/24212). For our analysis, we have grouped the latter two together, as they are both forms of private insurance. To investigate the relationship between drug coverage and the use of medications for chronic conditions, we analyzed questions that were asked specifically of respondents in Ontario who reported they had been diagnosed by a physician with one of the following three chronic conditions: asthma, high blood pressure or diabetes. These three chronic disease categories were selected because survey questions about diagnosis were followed up with questions about taking prescription drugs to treat. We believe that these conditions are important to consider because they are not only highly prevalent (MOHLTC 2007) but are also commonly treated with prescription drugs.

\section{Study cohorts}

First, we used three cohorts of respondents who reported having been diagnosed by a physician with one of three common chronic conditions: asthma, high blood pressure and diabetes. Within each of these three cohorts, we stratified our analysis into two age strata: individuals aged under 65 years and individuals aged 65 years and over. We used weighted samples provided by the CCHS. The total sample size for all three cohorts was 2,161,311. Table 1 demonstrates the weighted sample size for each cohort. For the under- 65 years' age stratum, 
we compared individuals with private coverage and individuals who reported having no coverage. We excluded those with public coverage in this age cohort because, by qualifying for public coverage, they were either low income (social assistance recipients) or had very high drug expenditures relative to their household income and were, therefore, not comparable to those with private insurance. For the 65 years and over stratum, we compared those with private coverage and those with public coverage, as all Ontario residents aged 65 years and over automatically qualify for universal public coverage.

TABLE 1. Weighted sample sizes of respondent disease cohorts

\begin{tabular}{|c|c|c|}
\hline Cohort & Age strata & Weighted sample size \\
\hline \multirow[t]{2}{*}{ Asthma } & under 65 & 494,628 \\
\hline & $65+$ & 60,622 \\
\hline \multirow[t]{2}{*}{ High blood pressure } & under 65 & 744,770 \\
\hline & $65+$ & 371,438 \\
\hline \multirow[t]{2}{*}{ Diabetes } & under 65 & 318,107 \\
\hline & $65+$ & $17 \mid, 746$ \\
\hline Total & & $2,|6|, 3 \mid 1$ \\
\hline
\end{tabular}

\section{Statistical analysis}

We investigated the relationship between holding private drug coverage and the use of medications for chronic conditions. In non-randomized study designs, the treated and control groups may have large differences in both their observed and unobserved covariates, and these differences can lead to biased estimates of treatment effects. The propensity score method can be used to balance the observable covariates between the groups with the hope of reducing this bias (Rubin 1997). Using a sample survey, however, it is also necessary to incorporate survey weights into the analysis (Zanutto et al. 2005). Therefore, we applied a propensity score method based on stratification that allows the incorporation of survey weights into estimates of the treatment effect (Zanutto 2006). We incorporated the survey weights after the propensity score sub-classification to make population-level inferences, and then used the adjusted weights as the normalized weights to estimate the average outcome.

In our study, the main determinant of interest was an individual's specific type of drug coverage. We needed to consider baseline covariates strongly associated with the use of medications and plausibly associated with having drug coverage, and we used propensity score stratification models to compare the prevalence of drug usage between drug coverage groups after accounting for baseline covariates. As we know from existing literature, individuals with and without private drug coverage are quite divergent on many characteristics (Dewa et al. 2005). We chose to use propensity score stratification over traditional regression approaches because it bases the results on comparisons between cohorts with similar observed characteristics. 
In our first step, we calculated a propensity score for each respondent which reflected their probability of having drug coverage using logistic regression. In the model, we included the baseline covariates of age, sex, marital status, current residence, immigration status, household size, income, education, employment status, chronic conditions and health status measures of the number of pre-existing conditions (see Appendix 2, Tables 7-12 at www. longwoods.com/content/24212). Note, in the model for the 65 years and over cohort diagnosed with asthma, we were required to drop the household size variable to reach convergence when performing the regression. This issue, while a frequent problem in estimating logistic regression models, did not occur in any of the other five models.

We followed recommended practice and created five strata of equal size, as this number of stratum has been shown to remove approximately $90 \%$ of bias in prior studies (Cochran 1968). Subsequently, we confirmed that the observed characteristics of the groups with and without private drug coverage were balanced within each of the three cohorts (Rosenbaum and Rubin 1984). We evaluated the extent to which the balance of the distribution of covariates for two groups was similar within each stratum using statistical tests with respect to the measuring scale of selected covariates (recognizing discrete, count and continuous outcomes) (Stampf 2011). P-values from these tests were applied to data before and after stratification to test the extent to which the propensity score model increased comparability between the two drug coverage groups within each stratum for all baseline covariates.

We estimated the probability of using drugs within each stratum and also estimated the overall probability as a weighted average. Finally, we used an indirect post-stratification adjustment to the final survey weights to estimate an overall survey-weighted probability in the overall population (Zanutto et al. 2005). To obtain the adjusted odds ratio for respondents with one drug coverage compared with those with another after adjusting for the probability of having drug coverage, we used a survey-weighted logistic regression model with the propensity score quintile serving as a summary confounder variable (Hahs-Vaughn and Onwuegbuzie 2006). All reported results are from weighted samples. In this model, the drug coverage variable is used as the independent variable, along with four of the five dummy-coded strata (see Appendix 2, Tables 7-12 at www.longwoods.com/content/24212). All analyses were performed using SAS, Version 9.2.

\section{Results}

Of the 21,991 respondents from Ontario, 12,833 reported holding employer-sponsored drug coverage. Overall, the use of propensity score stratification limited the extent to which each stratum differ based on these estimated differences in observed covariates (see Appendix 1, Tables 1-6 at www.longwoods.com/content/24212).

\section{Under 65 years}

All our models of the patients under 65 years of age compared those who reported holding private drug against the population that reported no coverage. This latter group would all be 
potentially eligible for the high-deductible public coverage of the Trillium Program. These results consistently showed that the individuals with private drug coverage had higher use of prescription drugs for their chronic conditions than those without.

\section{ASTHMA}

Patients with asthma in the under 65 years' cohort had a different likelihood of using prescribed drugs depending on whether they held private drug coverage. Table 2 shows the estimates of the effect of having drug coverage on the prevalence of drug usage when comparing groups with private coverage and groups with no coverage. Patients with asthma in the under 65 years' cohort had a different likelihood of using prescribed drugs depending on whether they held private drug coverage. The overall survey-weighted adjusted probability estimates indicate a modest difference in the prevalence of drug usage between these two groups (77.7\% vs. $70.9 \%)$. We found that individuals with private drug coverage had 1.5 times greater odds of having used prescription drugs to treat asthma than those without (OR $=1.50 ; 95 \%$ CI $[1.47,1.53])$.

TABLE 2. Drug utilization prevalence for respondents under the age of 65 years

\begin{tabular}{|c|c|c|c|c|}
\hline \multirow{2}{*}{$\begin{array}{l}\text { Under } 65 \text { years } \\
\text { Asthma }\end{array}$} & \multicolumn{3}{|c|}{$\begin{array}{l}\text { Private vs. none, } \\
\text { prevalence }\end{array}$} & \multirow{2}{*}{$\begin{array}{l}\text { Private vs. none, odds ratio } \\
O R=1.499[1.471,1.528]\end{array}$} \\
\hline & $77.7 \%$ & vs. & $70.9 \%$ & \\
\hline High blood pressure & $82.2 \%$ & vs. & $76.1 \%$ & $\mathrm{OR}=1.526[1.504,1.548]$ \\
\hline Diabetes & $79.3 \%$ & vs. & $71.2 \%$ & $\mathrm{OR}=1.158[1.129,1.186]$ \\
\hline
\end{tabular}

\section{HIGH BLOOD PRESSURE}

The prevalence of drug usage among individuals aged under 65 years with high blood pressure between individuals with private coverage and those without is shown in Table 2. Overall, survey-weighted probability estimates of drug usage for individuals with private insurance were moderately higher at $82.2 \%$ compared to $76.1 \%$ for individuals with only public coverage. Similar to the results for asthma, we found that individuals with private coverage had 1.5 times higher odds of having used prescribed drugs to treat high blood pressure than individuals with no coverage ( $\mathrm{OR}=1.53,95 \% \mathrm{CI}[1.50,1.55])$.

\section{DIABETES}

The prevalence of drug usage for individuals aged under 65 years with diabetes differed between those with private coverage and those without (79.3\% and $71.2 \%$, respectively). As shown in Table 2, after adjusting for quintile of propensity score, we found that individuals with private coverage had 1.2 times higher odds of having taken their prescribed diabetes drugs than individuals without $(\mathrm{OR}=1.16,95 \% \mathrm{CI}[1.13,1.19])$. 


\section{Individuals aged 65 years and older}

All patients in the cohorts of patients aged 65 years and older held some form of drug coverage: all comparisons are between the group that reported holding private drug coverage (those who would also be eligible for the ODB coverage) and the group with just public coverage. In total, 603,806 patients were aged 65 and older, representing $28 \%$ of the total sample.

\section{ASTHMA}

In the over- 65 years' cohort that reported physician-diagnosed asthma, drug usage varied between the group who reported holding private coverage and the group with only public coverage. Table 3 shows the overall survey-weighted probability estimates of drug usage between these two groups, with $92.5 \%$ patients with private coverage using prescribed drugs compared to $86.5 \%$ patients on the public plan. In adjusted models, cohort members with private coverage had 2.1 times higher odds of having used prescribed asthma drugs than those with public coverage $(\mathrm{OR}=2.12 ; 95 \% \mathrm{CI}[1.98,2.26])$.

TABLE 3. Drug utilization prevalence for respondents aged $65+$ years

\begin{tabular}{|c|c|c|c|c|}
\hline \multirow{2}{*}{$\begin{array}{l}\text { 65+ years } \\
\text { Asthma }\end{array}$} & \multicolumn{3}{|c|}{$\begin{array}{l}\text { Private vs. public, } \\
\text { prevalence }\end{array}$} & \multirow{2}{*}{$\begin{array}{l}\text { Private vs. public, odds ratio } \\
\mathrm{OR}=2.119[1.984,2.263]\end{array}$} \\
\hline & $92.5 \%$ & vs. & $86.5 \%$ & \\
\hline High blood pressure & $97.3 \%$ & vs. & $97.4 \%$ & $\mathrm{OR}=0.946[0.880,1.005]$ \\
\hline Diabetes & $88.9 \%$ & vs. & $84.1 \%$ & $\mathrm{OR}=1.327[1.276,1.380]$ \\
\hline
\end{tabular}

\section{HIGH BLOOD PRESSURE}

The type of drug coverage does not appear to impact drug usage for individuals aged 65 years and older with high blood pressure. This finding is in contrast to that of every other cohort we studied. As indicated in Table 3, the overall survey-weighted probability estimates for individuals with private coverage is $97.3 \%$, whereas the prevalence of drug usage for individuals with public coverage was strikingly similar at $97.4 \%$. The likelihood of an individual with private insurance taking their prescribed high blood pressure drugs in adjusted results was not statistically different from individuals who had only public coverage $(\mathrm{OR}=0.95 ; 95 \% \mathrm{CI}$ $[0.88,1.01])$.

\section{DIABETES}

The prevalence of drug usage to treat diabetes, as demonstrated in Table 3, was higher among individuals with private coverage than among those with public insurance $(88.9 \%$ and $84.1 \%$, respectively). Similar to the other cohorts in our study, respondents with diabetes who had private coverage were more likely to take their prescribed medications than those with public coverage based on adjusted results $(\mathrm{OR}=1.33[1.28,1.38])$. 


\section{Discussion}

Unlike universal coverage for hospital and physician services, there is significant variation in the coverage that Ontarians have to prescription drug insurance coverage. We found that these differences in coverage are associated with significant differences in drug utilization for individuals with three very common chronic conditions. Our results indicate that Ontarians with chronic conditions who are enrolled in a private benefits' plan are more likely to take the associated medications than those with public coverage or no drug coverage at all in five of our six cohorts. This study is consistent with previous results that have shown private coverage to increase drug utilization in those aged over 65 years (Allin et al. 2013). Further, it extends these results and shows that the differences are even larger for those aged under 65 years. These differences reflect inequities in access to medicines based on insurance coverage and also likely result in differences in health outcomes between individuals with and without private coverage.

Distinctly identifying the importance of insurance coverage on impacting access to medicines makes an important contribution to our understanding of how to reduce barriers to access. Prior studies in this area have identified several individual characteristics that impact access, such as age, chronic conditions, education and income (Osterberg and Blaschke 2005; Tamblyn et al. 2014). Insurance coverage type, unlike the other aforementioned characteristics, is very policy amenable. For example, policy makers may not be able to directly change the education or income level of individuals, but they do have the capacity to modify the availability and comprehensiveness of public insurance coverage plans. This could include lower deductibles and copayments that patients are required to pay out-of-pocket.

Comparing individuals reporting private plans with those reporting either public coverage or being uninsured reveals some important differences. With the exception of individuals aged 65 years and over with high blood pressure, all the chronic condition cohorts we studied showed that private drug coverage is linked to a greater likelihood of taking one or more of the associated prescribed medications for that condition. There are two key differences in the structure of private and public plans: the first being the size of the out-of-pocket payments paid by patients and the second is that public drug plans have a strict formulary, while most private plans do not (Kratzer et al. 2013). Given that the uninsured do not have any formulary, it seems less likely that this aspect of plan structure is a barrier to care and is not a determining factor in private plan patients having a greater likelihood of taking their medications.

This study suggests that the identified differences in the prevalence and the likelihood of taking prescription drugs likely result from how the availability of private insurance (or lack thereof) impacts the out-of-pocket payments that would be required of patients. This, of course, varies between our two age cohorts. Individuals aged under 65 years who do not have prescription drug coverage would be required to pay for all of their prescriptions out of their own pocket up to the Trillium Drug Program deductible (typically, 4\% of household income). 
In contrast, those with private coverage typically pay a \$25-50 deductible and some copayment (most typically 20\% coinsurance) (Kratzer et al. 2013). In the case of individuals aged 65 years and over, the public ODB plan would require patients to make a small copayment for covered medicines. In this case, private plans normally pay most, if not all, of these copayment amounts, making prescriptions systematically less expensive for this group.

\section{Limitations}

There are limitations to this study worth noting. As with any survey, there is the potential for recall bias by participants. This may be true for patients who hold private drug coverage but do not use it. However, any such misreporting would likely have biased our results toward the null. There are potentially unobserved covariates that therefore have not been controlled for by the propensity score stratification. The survey did not provide information on type of employer or whether an individual was employed full or part-time, both of which are predictive of holding private employer-based insurance. Survey questions did not ask about adherence to medicines. We could only study the disease groups that questions were asked about in the CCHS survey; thus, we cannot be sure that our findings hold across other disease groups. We also could not assess whether the medicines prescribed to patients were included on the provincial formulary. Finally, the survey only measured self-reported drug use; however, our findings are consistent with those of the prior research that used administrative claims data in Ontario (Allin et al. 2013). It is impossible to know if our propensity score-matching techniques eliminated all residual confounding factors. However, as we know that the holders of private insurance are typically wealthier and healthier than those who do not, this likely would only act to make our comparisons conservative in nature.

\section{Conclusion}

Our results are highly suggestive that inequities in access to prescription drugs result from differences in access to prescription drug coverage. Overall, we found that individuals with private prescription drug coverage are more likely to take prescribed medications. This finding was consistent across five of the six groups we analyzed that encompassed three different highly prevalent chronic conditions. In particular, we found that for Ontarians aged under 65 years, private drug coverage was a major determinant in drug use for individuals with three major chronic conditions. This narrowing of the differences likely represents the impact of the universal public drug benefit for those aged over 65 years. Overall, however, our study indicates that Ontarians who have private drug insurance have greater access to prescription drugs than those who do not. 


\section{Acknowledgements}

This research was funded by an operating grant from the Canadian Institutes of Health Research ("For Whom the Bill Tolls: Private Drug Insurance in Canada", P.I. Michael Law). Michael Law received salary support through a New Investigator Award from the Canadian Institutes of Health Research and a Scholar Award from the Michael Smith Foundation for Health Research.

Correspondence may be directed to: Michael R. Law, PhD, Centre for Health Services and Policy Research, School of Population and Public Health, Faculty of Medicine, University of British Columbia, 201-2206 East Mall, Vancouver, BC, V6T 1Z3; e-mail: michael.law@ubc.ca.

\section{References}

Adams, A.S., S.B. Soumerai and D. Ross-Degnan. 2001.“Use of Antihypertensive Drugs by Medicare Enrollees: Does Type of Drug Coverage Matter?" Health Affairs 20(1): 276-86.

Allin, S. and J. Hurley. 2009. "Inequity in Publicly Funded Physician Care: What is the Role of Private Prescription Drug Insurance?" Health Economics 18(10): 1218-32. doi:10.1002/hec.1428.

Allin, S., M.R. Law and A. Laporte. 2013. “How Does Complementary Private Prescription Drug Insurance Coverage Affect Seniors' Use of Publicly Funded Medications?” Health Policy 110(2-3): 147-55. doi:10.1016/j. healthpol.2013.02.010.

Canadian Institute for Health Information (CIHI). 2013. Drug Expenditure in Canada, 1985 to 2012. Ottawa, ON: Author. <https://secure.cihi.ca/free_products/Drug_Expenditure_2013_EN.pdf>

Cochran, W.G. 1968. "The Effectiveness of Adjustment by Subclassification in Removing Bias in Observational Studies." Biometrics 24(2): 295-313.

Daw, J.R. and S.G. Morgan. 2012. “Stitching the Gaps in the Canadian Public Drug Coverage Patchwork? A Review of Provincial Pharmacare Policy Changes from 2000 to 2010." Health Policy 104(1): 19-26. doi:10.1016/j. healthpol.2011.08.015.

Dewa, C.S., J.S. Hoch and L. Steele. 2005. “Prescription Drug Benefits and Canada's Uninsured.” International Journal of Law and Psychiatry 28(5): 496-513. doi:10.1016/j.jilp.2005.08.003.

Fang, H., M.P. Keane and D. Silverman. 2008. "Sources of Advantageous Selection: Evidence from the Medigap Insurance Market." Journal of Political Economy 116(2) 303-50. doi:10.1086/587623.

Fraser Group/Tristat Resources. 2002. Drug Expense Coverage in the Canadian Population: Protection from Severe Drug Expenses (p. 55). Retrieved April 15, 2015. <http://www.frasergroup.com/downloads/severe_drug_e.pdf >.

Goldman, J.G.F. and Y. Zheng. 2007. “Prescription Drug Cost Sharing: Associations with Medication and Medical Utilization and Spending and Health." JAMA 298(1): 61-69. doi:10.1001/jama.298.1.61.

Government of Canada, S. C. (2012, September 27). Population by Year, by Province and Territory. Retrieved November 4, 2013. <http://www.statcan.gc.ca/tables-tableaux/sum-som/101/cst01/demo02a-eng.htm>.

Government of Ontario, M. of H. and L.-T. C. (n.d.-a). Ontario Public Drug Programs - Public Information MOHLTC. Retrieved September 23, 2013. <http://www.health.gov.on.ca/en/public/programs/drugs/programs/ programs.aspx $>$.

Government of Ontario, M. of H. and L.-T. C. (n.d.-b). Trillium Drug Program - Public Information - MOHLTC. Retrieved September 23, 2013. <http://www.health.gov.on.ca/en/public/programs/drugs/programs/odb/opdp_ trillium.aspx $>$. 
Hahs-Vaughn, D.L. and A.J. Onwuegbuzie. 2006."Estimating and Using Propensity Score Analysis with Complex Samples." The Journal of Experimental Education 75(1): 31-65. doi:10.3200/JEXE.75.1.31-65.

Hanley, G.E. 2009. "Prescription Drug Insurance and Unmet Need for Health Care: A Cross-Sectional Analysis.” Open Medicine 3(3).

Joyce, G.F., J.J. Escarce, M.D. Solomon and D.P. Goldman. 2002. “Employer Drug Benefit Plans and Spending on Prescription Drugs. JAMA 288(14).

Kratzer, J., K. McGrail, E. Strumpf and M.R. Law. 2013. “Cost-Control Mechanisms in Canadian Private Drug Plans." Healthcare Policy 9(1): 35-43. doi:10.12927/hcpol.2013.23479.

Law, M.R., L. Cheng, I.A. Dhalla, D. Heard and S.G. Morgan. 2012.“The Effect of Cost on Adherence to Prescription Medications in Canada." Canadian Medical Association Journal 184(3): 297-302. doi:10.1503/ cmaj.111270.

Law, M.R., J. Kratzer and I.A. Dhalla. 2014. “The Increasing Inefficiency of Private Health Insurance in Canada." Canadian Medical Association Journal 186(12): e470-e474.

Marshall, K. 2003. "Benefits of the Job." Perspectives on Labour and Income 4(5): 5-12.

Millar, W.J. 1999. Disparities in Prescription Drug Insurance Coverage. Health Reports/Statistics Canada, Canadian Centre for Health Information = Rapports sur la santé/Statistique Canada, Centre canadien d'information sur la santé 10(4) : 11-31(ENG); 9-30(FRE).

Ministry of Health and Long-Term Care (MOHLTC). 2007. (May). Preventing and Managing Chronic Disease: Ontario's Framework. Retrieved April 5, 2015. <http://www.health.gov.on.ca/en/pro/programs/cdpm/pdf/framework_full.pdf>.

Morgan, S.G., J.R. Daw and M.R. Law. 2013. Rethinking Pharmacare in Canada. Toronto, Canada: CD Howe Institute.

Osterberg, L. and T. Blaschke. 2005. "Adherence to Medication." The New England Journal of Medicine 353(5): 487-97. doi:10.1056/NEJMra050100.

Rosenbaum, P.R. and D.B. Rubin. 1984. “Reducing Bias in Observational Studies Using Subclassification on the Propensity Score." Journal of the American Statistical Association 79(387): 516-24. doi:10.2307/2288398.

Rubin, D.B. 1997. “Estimating Causal Effects from Large Data Sets Using Propensity Scores." Annals of Internal Medicine 127(8 Part 2): 757-63. doi:10.1059/0003-4819-127-8_Part_2-199710151-00064.

Soumerai, S.B. 2004. "Benefits and Risks of Increasing Restrictions on Access to Costly Drugs in Medicaid." Health Affairs 23(1).

Stabile, M. 2001. "Private Insurance Subsidies and Public Health Care Markets: Evidence from Canada," The Canadian Journal of Economics/Revue canadienne d'economique 34(4): 921-42.

Stampf, S. 2011. Propensity Score Based Data Analysis Using Nonrandom. Retrieved April 5, 2015. $<$ http://130.203.133.150/viewdoc/summary?doi=10.1.1.190.8730>.

Tamblyn, R., T. Eguale, A. Huang, N. Winslade and P. Doran. 2014." The Incidence and Determinants of Primary Nonadherence with Prescribed Medication in Primary Care: A Cohort Study Primary Nonadherence with Prescribed Medication in Primary Care." Annals of Internal Medicine 160(7): 441-50. doi:10.7326/M13-1705.

Tamblyn, R., R. Laprise, J.A. Hanley, M. Abrahamowicz, S. Scott, N. Mayo et al. 2001. “Adverse Events Associated with Prescription Drug Cost-Sharing among Poor and Elderly Persons." JAMA 285(4): 421-9.

Zanutto, E. 2006. "A Comparison of Propensity Score and Linear Regression Analysis of Complex Survey Data." Journal of Data Science 4(1): 67-91.

Zanutto, E., B. Lu and R. Hornik. 2005. “Using Propensity Score Subclassification for Multiple Treatment Doses to Evaluate a National Antidrug Media Campaign." Journal of Educational and Behavioral Statistics 30(1): 59-73. doi:10.3102/10769986030001059. 